\title{
Silva Jardim: a República e o vulcão
}

\author{
FRANCISCO FOOT HARDMAN
}

Para Paula

Bela sepultura o vulcão, extraordinário destino o do grande brasileiro; até para morrer converteu-se em lava.

(José do Patrocínio, O Seculo, 12/7/1891)

O Vesúvio curioso quis saber dele como é que irrompem dos grandes vulcões sociais, dessas crateras que se abrem surdamente na terra da politica, essas erupções medonhas de lavas e de cinzas, de fogo que tudo purifica, e de lama que tudo mancha, que se chamam Revoluções.

(Pinheiro Chagas, O Paiz, 20/7/1891)

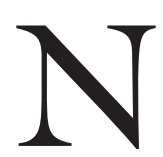

A CONJUNTURA Do final do século XIX a obra de Silva Jardim, em especial este volume tão impressionante e estranho que é o de suas Memórias e viagens (1891) - por ele concebido e organizado, mas surgido já postumamente -, vincula-se de modo trágico à sua morte precoce, aos 31 anos, tragado pela cratera do Vesúvio, pondo fim à utopia republicana das mais radicais dentre as que combateram pelo fim da escravidão e da monarquia, ele próprio por todos tido e havido como o maior propagandista e agitador político do novo regime, o qual levaria, pelas ironias do destino e pelos meandros da política de conciliação conservadora (entre militares, republicanos históricos e oligarquias agrárias) um de seus mais ardorosos artífices ao auto-exílio em Paris e ao abismo vulcânico em Nápoles.

Essa trajetória única em termos políticos e pessoais mantém, no entanto, elos significativos com outras experiências literárias e ideológicas daquele momento histórico. Trata-se do que tenho denominado de linhagem do "desencanto ou desilusão do progresso". Suas raízes mais remotas repousam em matrizes da concepção de mundo do romantismo, associadas de forma intensa a representações simbólicas do sublime. Nessa vertente, que acompanha de perto o vulcanismo de Silva Jardim, estão presentes escritores importantes, entre outros, Raul Pompéia (já em O ateneu, mas sobretudo em Canções sem metro); Gonzaga Duque (em particular, nessa obra esquecida e inovadora que é Revoluções brasileiras); Cruz e Sousa (em especial, na 
prosa dramática de Evocações e na poesia desencantada de Faróis); Euclydes da Cunha (antes, durante e depois de Os sertões); Alberto Rangel (em Inferno verde e em Sombras n'água, mas também em crônicas inéditas como essa "Pitoresco e estafa", de 1908, tendo como cenário, Nápoles, e como motivo, uma excursão ao Vesúvio); e Lima Barreto (quem duvida que $O$ triste fim de Policarpo Quaresma participa desse mesmo filão disfórico?).

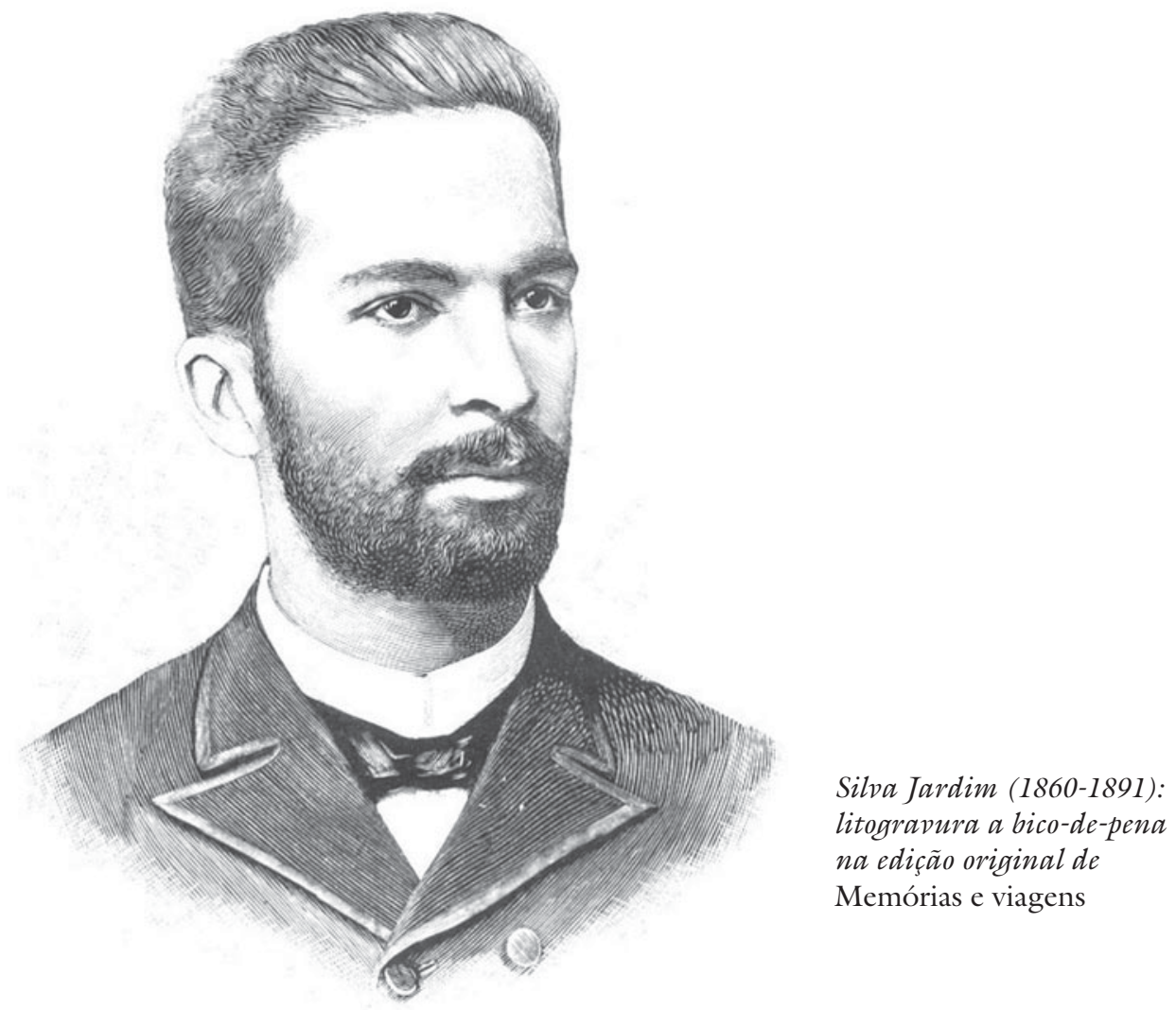

Continuo, aqui, a perseguir a mesma tese: a morte de Silva Jardim, para além do relato biográfico ou do episódio trágico de jornal, foi emblemática sobre os limites da nova ordem republicana, anunciando a crise do sublime romântico como representação possível de uma natureza infinita e do poder transformador radical e utópico da linguagem. Pretendo assinalar, a seguir, que, fiel a esse utopismo romântico e revolucionário, Jardim esteve sempre fascinado, em sua vida, em seus discursos, na memória e até na morte, por experimentar as fronteiras últimas do desconhecido: abyssus abyssum evocat. Foi coerente nas escolhas, ousado nas ações, temerário na solidão. Ao lado dele, firmou-se a visão dissidente dos rebeldes radicais que permaneceram, com seus escritos, sonhos, ações e iluminações, nas margens da história, logo desconfiantes dos rumos da nova ordem republicana. Nas margens da política e da literatura oficiais. Mas essa já é uma outra e longa história. 


\section{A república sublimada}

A República por que Silva Jardim lutou ardorosamente como um dos maiores oradores populares do Brasil do século XIX (cf. Jardim, 1891; 1978), como tantos outros homens de sua geração, remonta às construções mais arcaicas e radicais do direito romano, do pensamento iluminista, dos jacobinistas e ideólogos de 1789, da idéia de cidadania nacional na transição ao romantismo oitocentista entre franceses, alemães e italianos (cf. Thom, 1995); daí resultando conjunto de valores e concepções que se ancoravam de modo intransigente na defesa de um espaço público e na subordinação incondicional de qualquer mecanismo de representação política à vontade do povo.

Evidente que essa posição, de resto revolucionária e que poderia, com efeito, se encaminhar para uma perspectiva social-democrata plena, encontrou fortíssimas barreiras para se firmar na conjuntura política imediatamente posterior ao 15 de novembro de 1889. Daí o relativo ostracismo e auto-exílio prematuro de Silva Jardim em face dos militares e republicanos históricos que instalaram o novo regime. Daí que sua República vira desde logo um sonho, um projeto sublimado, grandioso e inalcançável como as paisagens que o seduziam.

A esse propósito, talvez uma das passagens mais esclarecedoras de suas Memórias sejam as páginas em que, melancólico, recorda-se de seu gabinete de trabalho, de sua biblioteca particular nos tempos da campanha republicana, convidando o leitor a um "passeio pelas suas estantes" (Jardim, 1891:214; cf. todo o trecho entre as páginas 213 e 224). Aqui, temos a sublimação por esse quase infinito parque da cultura letrada, os livros como fonte inspiradora de trabalho e prazer, mas igualmente como índices de recolhimento da solidão revolucionária:

São os meus companheiros. Os vivos dão-vos tantos desgostos que é grande consolo o contacto com estes mortos, que entretanto vos falam como se fossem vivos.

(...) só ela, a ciência, inspirada no amor social, e acompanhada da poesia, vos consola; e os mortos célebres, os grandes abnegados se vos apresentam então, bons, simples, amigos que não traem, conselheiros que não enganam (p. 222).

Mas, no trecho seguinte evoca, como faria Gonzaga Duque em livro vulcânico poucos anos depois (1898; 1905), os mártires revolucionários, dos movimentos de 1720 (Felipe dos Santos) a 1848 (Pedro Ivo), para dramaticamente sublinhar:

Animava-me com a evolução do Brasil onde não podiam medrar as instituições do privilégio, individualmente, e da tirania, já pelo 'meio' morto, 
celeste ou telúrico, já pelo 'meio' vivo, vegetal, animal ou humano. E o histórico das nossas revoluções gloriosas punba-me no sangue o ardor da fé que abala as montanhas (p. 223).

Para voltar, de novo, às estantes e à solidão da biblioteca, a essa comunicação sublime, transcendente de espaço-tempos, capaz de reunir saberes esparsos e aproximar a voz da poesia à da oratória, a visão da natureza à da política e à da história, república sublimada na viagem da palavra escrita e da memória:

Este, poeta, cantava a coragem dos heróis, ou os momentos de amor e de repouso na vida, ou o sorriso de ironia diante das fraquezas; este, sábio, fornecia pela contemplação da natureza as bases da convicção politica que est'outro, historiador, desenvolvia na apreciação dos estadistas; este, filósofo, lançava o olhar sereno sobre os tempos, e dava a lição moral a todos. Permitam este voto de agradecimento aos imortais e queridos mestres. Todos eles me incitavam ao combate pela libertação definitiva da mais bela das Pátrias" (p. 224).

A República sonhada por Jardim funda-se nessa estranha fusão entre humanismo iluminista e revolta romântica. Sua utopia será sempre extravagante. Sua beleza não deriva contudo só da poética do sublime, mas, ao mesmo tempo, sob forma algo indivisa, de uma ética rousseauniana inquebrantável.

\section{Sublimes panoramas}

Nesta seção, de forma sucinta, para se comparar relatos paralelos, transcreverei algumas passagens que confirmam a incorporação, radical e trágica, do sublime romântico em Silva Jardim. Entre outras evidências, tais vestígios apontam para o caráter não-acidental de sua morte, isto é, o acaso eventual do desfecho de um passeio perigoso pelas bordas não recomendadas do Vesúvio foi buscado determinadamente, como desejo absoluto de transcendência da história e da natureza, o fogo maior do centro da Terra desenhando a revolução impossível, a república sublimada dormindo sob os escombros arquetípicos de Pompéia, o Brasil tão amado em fragmentos de lava estranha, a solidão e o silêncio como sonhos sofridos deste verdadeiro mestre da palavra-ação, fundador de uma República que ainda não teve lugar.

É sempre bom frisar que tal imaginário, despertado pela aventura solitária diante de paisagens sublimes, já possuía lastro forte na tradição romântica, inclusive nacional (cf. Broca, 1993; Subirats, 1986; Weiskel, 1994). Um ótimo exemplo encontra-se na interessante novela de Joaquim Manuel de Macedo, A luneta mágica (1869), quando, já no final da trama, o narrador chega até o alto do morro do Corcovado e inicia uma contemplação melancólica da 
cidade do Rio de Janeiro; ali, em meio à neblina, entre os véus da cerração na madrugada, não se podia de início alcançar visão mais ampla e profunda da então capital do Império do Brasil. Com os primeiros raios do amanhecer, a paisagem se descortina:

(...) Não tentarei descrever o lindo, o belo, o sublime panorama, que por todos os lados, se abriu à minha luneta mágica, as cidades e povoados, as terras e o oceano, as montanhas e os abismos, os montes e os vales, as torrentes e as pedras, o céu e os campos, a providência, e o mundo, a riqueza do favor de Deus, e a miséria da incúria dos homens!!! (Macedo, 1990:156-157).

Mas o maravilhoso atrai sempre pelo seu lado mais terrível. Nesse romance, o narrador, proibido de antecipar uma visão do futuro (a luneta, ao se insistir nessa busca, perde seu encanto mágico e quebra-se em migalhas), deseja também a morte e se prepara para o suicídio:

Ter por extrema despedida do mundo o quadro aberto do futuro próspero da pátria, seria a mais suave consolação, se eu pudesse conseguir a visão do futuro antes de suicidar-me (p. 157).

Não há futuro visível, nem utopia palpável: apenas, além do parapeito do mirante, o profundo precipício.

Inusitado paralelo pode-se estabelecer entre esta passagem e um relato de Silva Jardim presente em suas memórias, a propósito de uma rara pausa em sua caravana de propagandista: convalescente de grave moléstia que o levara a se internar no hotel das Paineiras, em plena floresta do Corcovado, narra com indisfarçável prazer alguns dos passeios que essa trégua forçada acabara por lhe propiciar. Entre as digressões intimistas que só a doença conseguiu arrancar do homem público e apenas o recuo do registro memorialístico foi capaz de fixar, há uma significativa identificação que aproxima, como produtos históricos e não naturais, as revoluções do corpo, do espírito e da sociedade:

Não! a revolução, nem a do corpo, que a nós mesmos causamos pelo trabalho ou pelo gozo excessivo, nem a do espirito que os cuidados, os desgostos ou o estudo forçado nos determinam, nem a da sociedade, que os homens criam pelos seus desregramentos e que os reformadores fazem às vezes rebentar como mal necessário, não é cousa natural. Naturais são a paz e a ordem, numa liberdade serena. Nossa infeliz natureza é, porém, talmente constituida que quando gozamos o bem-estar da saúde fatigamos o pobre pedestal do cérebro a ponto de abalarmos a sede de toda a vida, que nele se concentra, e de provocarmos de novo a doença. Eu sou dos que pensam que nós não morremos, nós suicidamo-nos (Jardim, 1891:259, grifos meus). 


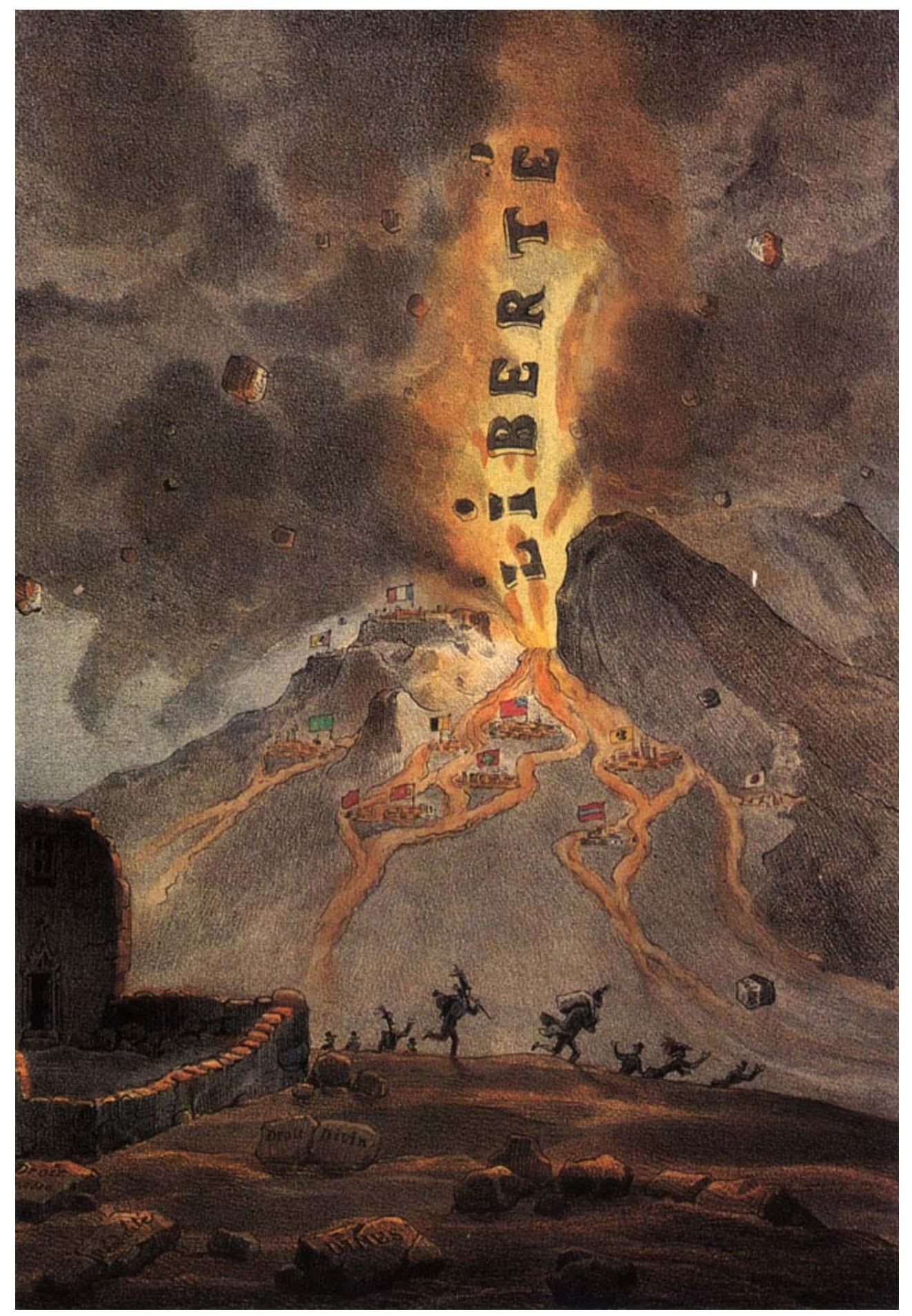

“Troisième Eruption du Volcan de 1789": litogravura publicada no jornal La Caricature, $n^{\circ} 135$ e reproduzida no livro de Maurice Krafft, Les Feux de la Terre: Histoires de Volcans, Paris, 1991. 
Mas é preciso, por assim dizer, radicalizar o passeio se se quiser alcançar o panorama mais sublime, a força telúrica e os devaneios da vontade, de que as revoluções humanas seriam antes imitações:

O Brasil, mesmo o Brasil belo pelas opulências da criação, está nessa maravilhosa cidade do Rio de Janeiro. Para vê-lo e para vê-la, é preciso subir, pela estrada do Corcovado, prodígio de arte, até o alto da montanha, até o seu pico, e dai olhar o panorama extasiante. Chamam a este monte o Corcovado; eu o chamaria o Indignado; tamanha é a atitude de vigor que toma este grito da terra, esta convulsão da natureza, arrojando ao céu a perpetuação de uma revolta no dia do parto gigantesco do continente novo, dia que a história do homem jamais consignará ao certo... Que poder estranbo de força natural conseguiu erguer este gigante bruto até tamanha altura?... (p. 259-260)

É esta atração pelos limites extremos, de uma alma inquieta, grandiosa e inconformada com os próprios limites do corpo, do espírito e da sociedade num espaço-tempo determinado; de um corpo que excedia as fronteiras do razoável e do realismo prudente na busca do sublime em sua máxima manifestação material, com visões capazes de incitar à revolução e à rebeldia permanente da alma; é esta fascinação absolutamente irresistível pelas bordas da morte que acabará selando, afinal, seu destino, desfazendo-se o corpo na mais elevada integridade do sonho - sonho de um caminhante solitário:

E quem quiser o repouso num silêncio apenas cortado pelo grito de algum pássaro, siga o antigo aqueduto. Era por aí que eu passeava pelas manbãs, só e pensativo, a ensaiar minhas forças de convalescente. Uma vez, - era ao meiodia - estendi meus passos até a Ponte do Inferno, onde vi alguma cousa de gigantesco e temivel. A Ponte do Inferno é uma ponte de madeira e de ferro; os engates estão cravados na rocha que ascende à direita, e à esquerda vai descendo e descendo até o abismo, donde nos vem um rumor confuso como de gemidos surdos, que a ventania produz, subindo pela pedra, aos encontrões com a vegetação. A velha ponte estava em ruinas; por um capricho de 'touriste' atravessei os seus cento e cinqüenta metros, agarrando-me aqui à calha que se estreitava, ali a um galbo de árvore ou a uma moita de arbustos. Embaixo, muito embaixo o Jardim Botânico ostentava a sua flora.

(...) passaram o resto do dia a censurar-me a imprudência. Maseu tinha visto alguma cousa de extraordinariamente belo, que só se vê uma vez na vida, nas poucas horas de lazer que a existência atribulada nos deixa (p. 260-261).

$\mathrm{Na}$ crônica fúnebre, publicada por Pinheiro Chagas no jornal O Paiz logo após a morte de Silva Jardim, em julho de 1891, há clara referência a esse encanto incon-trolável produzido por abismos naturais sobre o 
revolucionário da República, relatando-se outra cena análoga ocorrida pouco tempo antes da tragédia do Vesúvio, em Cascais, Portugal, num conjunto de penhascos à beira-mar conhecido como Boca do Inferno. Num passeio feito até lá, com o escritor Fernandes Costa, embora advertido sobre o extremo perigo, Jardim saltara pelos vãos da fímbria dos penedos, desafiando o espaço vazio e a fúria das ondas. $\mathrm{O}$ cronista ressalta o caráter regressivo, algo arcaico dessa morte no Vesúvio (relembra Empédocles, no Etna, e Plínio, o Velho, no mesmo Vesúvio que soterrou Pompéia, Herculano e Stabia), isso já em plena era do progresso industrial e das ferrovias. E conclui sua homenagem:

Quando se submergia, viram-no os seus companbeiros tapar os ouvidos com as mãos como se escutasse um ruido medonho. 'O ouvido atento', diz Soares de Passos, 'no silêncio das campas nada escuta.' O que ouviria ele naquela enorme rampa rugidora, que foi há dezenove séculos o túmulo de Plinio? (apud Jardim, 1891:453-458)

Talvez, nesses sublimes panoramas que tanto o atraíram e mataram, Silva Jardim, fiel a seu nome, olhasse e ouvisse, devaneadoramente, não só a infinitude sempre assustadora do deserto, o incomensurável de toda selva, a prata melancólica de uma lua sem fim, mas também, em algum meandro inatingível à vista comum, a possível simetria de um jardim, o recorte da arte moderna e pública da criação de parques, a composição, no meio de silvos e selvas medonhas, de um recanto humanamente reconciliado, de cidades habitáveis e praças agitadas, entre notas de um belo hino republicano.

Mas esse já é um exercício especulativo. Essa possível visão está morta, junto com seu visionário. Nossa república prosaica de cada dia é bem mais feia, injusta, excludente e particularista; nem chega a ser completamente pública. Perdeu, de há muito, no jogo cego das forças do mercado, qualquer fundamento moral. Seus acordes redundaram em harmonia de jingle. Não oferece, portanto, os sublimes panoramas buscados pelo autor de Memórias e viagens. Não é a utopia republicana radical que sua voz vulcânica anunciou, em várias praças e horas, em peregrinação vertiginosa, pelos quatro cantos do país e que se interrompeu, repentinamente, na voragem estrondosa de um vulcão. 
Referências bibliográficas

BROCA, J. Brito. Silva Jardim e a tragédia do Vesúvio. In: Teatro das letras. Campinas, Unicamp, 1993, p. 118-122.

CRUZ E SOUSA, João da. Obra completa. Rio de Janeiro, Nova Aguilar, 1995.

DORNAS FILHO, João. Silva Jardim. São Paulo, Nacional, 1936.

DUQUE, Gonzaga. Revoluções brasileiras: resumos históricos. Rio de Janeiro, Typographia do "Jornal do Commercio", 1898; 2 . ed.: Rio de Janeiro, Laemmert \& C., 1905.

HARDMAN, F. Foot. Antigos modernistas. In: Novaes, A. (org.). Tempo e história. São Paulo, Cia. Letras; Secretaria Municipal de Cultura, 1992, p. 289-305.

Brutalidade antiga: sobre história e ruína em Euclides. In: Estudos Avançados, v. 10, n. 26, p. 293-310, jan./abr. 1996.

Duas viagens a Nápoles. Rio de Janeiro, Fundação Casa de Rui Barbosa, 1998 (Papéis Avulsos, 32).

1988.

Trem fantasma: a modernidade na selva. São Paulo, Cia. Letras,

JARDIM, Antônio da Silva. Memórias e viagens (I - Campanba de um propagandista, 1887-1890). Lisboa, Typ. Comp. Nacional, 1891.

Propaganda republicana (1888-1889). Rio de Janeiro, Fundação

Casa de Rui Barbosa, 1978.

KRAFFT, Maurice. Les feux de la Terre: histoires de volcans. Paris, Gallimard, 1991.

LEÃO, José. Silva Jardim: apontamentos para a biografia do ilustre propagandista. Rio de Janeiro, Imprensa Oficial, 1895.

LIMA, Heitor Ferreira. Perfil político de Silva Jardim. São Paulo, Nacional; Brasília, INL, 1987.

MACEDO, Joaquim Manuel de. A luneta mágica, 6ª . ed. São Paulo, Ática, 1990.

PINHEIRO CHAGAS. [Artigo à memória de Silva Jardim]. In: Jardim, Silva. Memórias e viagens (I - Campanha de um propagandista, 1887-1890). Lisboa, Tip. da Comp. Nacional, 1891, p.453-458.

POMPÉIA, Raul. Canções sem metro. Rio de Janeiro, Civilização Brasileira, 1982 (Obras, IV).

QUEIRÓS, Maurício Vinhas de. Uma garganta e alguns níqueis. Rio de Janeiro, Aurora, 1947. 
RANGEL, Alberto. Pitoresco e estafa. In: Hardman, F. Foot. Duas viagens a Nápoles. Rio de Janeiro, Fundação Casa de Rui Barbosa, 1998, p. 31-40.

SUBIRATS, Eduardo. Paisagens da solidão: ensaios sobre filosofia e cultura. São Paulo, Duas Cidades, 1986.

THOM, Martin. Republics, nations and tribes. London/New York, Verso, 1995.

WEISKEL, Thomas. O sublime romântico: estudos sobre a estrutura e psicologia da transcendência. Rio de Janeiro, Imago, 1994.

Francisco Foot Hardman é professor na área de Literatura e Outras Produções Culturais do Departamento de Teoria Literária do Instituto de Estudos da Linguagem da Universidade Estadual de Campinas (Unicamp). É autor, entre vários artigos e livros, de Nem pátria, nem patrão: vida operária e cultura anarquista no Brasil (1983) e Trem fantasma: a modernidade na selva (1988). 